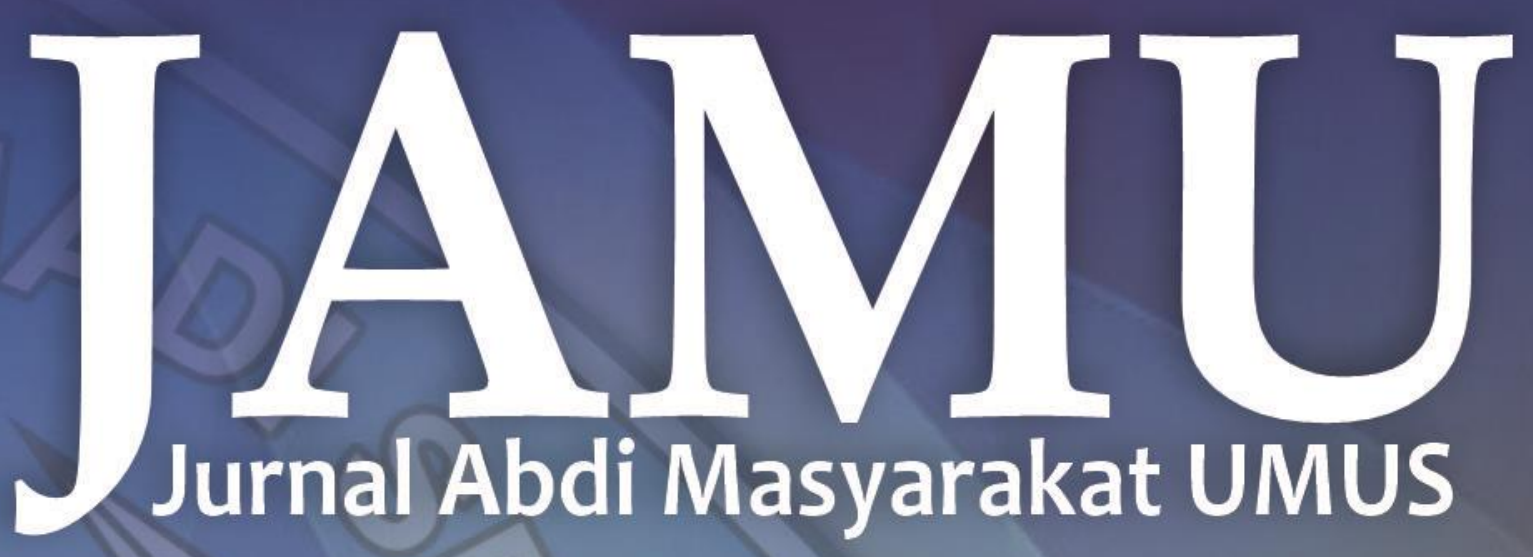




\section{EDITOR IN CHIEF}

Ubaedillah, M.Pd

\section{MANAGING EDITOR}

Harliana, ST., M.Cs

\section{PRINCIPAL CONTACT}

Rifatul Masrikhiyah, S.Tp., M.Si

\section{SUPPORT CONTACT}

Laelia Nurpratiwiningsih, M.Pd

\section{MITRA BESTARI (STAFF AHLI)}

Dr. Roby Setiadi, S.Kom., M.M (Universitas Muhadi Setiabudi, Brebes)

Otong Saeful Bachri, S.Kom., M.Kom (Universitas Muhadi Setiabudi, Brebes)

Dr. Moh. Toharudin, M.Pd (Universitas Muhadi Setiabudi, Brebes) Atikah Mumpuni, M.Pd (Universitas Muhadi Setiabudi, Brebes)

Dr. Heru Ismanto, S.Si., M.Cs (Universitas Musamus Merauke, Papua) Dr. Wuri Wuryandani, M.Pd (Universitas Negeri Yogyakarta)

Dr. Nanik Sulistyani, M.Si., Apt (Universitas Ahmad Dahlan, Yogyakarta)

Dina Rahayuning Pangestuti, S.TP., M.Gizi (Universitas Diponogoro) Jasanta Peranginangin, S.E., M.M (Sekolah Tinggi Pariwisata Sahid Surakarta)

Dr. Lili Karmela Fitriani, S.E., M.Si (Universitas Kuningan, Jawa Barat)

\section{PENANGGUNGJAWAB :}

Rektor Universitas Muhadi Setiabudi Brebes

\section{ALAMAT PENYUNTING:}

LP3M Universitas Muhadi Setiabudi Brebes.

Jalan Pangeran Diponogoro KM 2 Wanasari Brebes - Jawa Tengah 52252. Telp (0283) 6199000 


\section{JAMU}

Jurnal Abdi Masyarakat UMUS

\section{KATA PENGANTAR}

Assalamualaikum Wr, Wb

Puji syukur kehadirat Allah SWT atas anugrahnya sehingga jurnal edisi kali ini dapat terbit. Sebelumnya kami ingin mengucapkan terimakasih banyak kepada dosen/peneliti/profesi yang telah mengirimkan artikelnya kepada dewan redaksi untuk dapat dipublish pada jurnal yang kami kelola. Semua artikel yang masuk kepada dewan redaksi telah melalui proses review oleh mitra bestari dan tim dewan redaksi, segala proses revisi dan redaksional juga telah dilakukan oleh penulis sebelum jurnal ini diterbitkan. Segala bentuk kritik dan saran yang membangun dari pembaca / peneliti yang dikirimkan sangat kami harapkan demi melakukan pembenahan jurnal yang kami kelola. Akhir kata kami menghaturkan terimakasih banyak kepada semua pihak yang sudah terlibat dalam proses penerbitan jurnal ini.

Wassalamualaikum wr wb.

Ketua Dewan Redaksi 


\section{DAFTAR ISI}

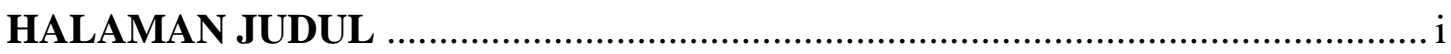

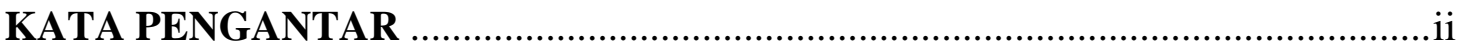

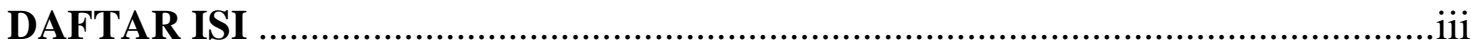

Pemberdayaan Anak Usia Sekolah Dalam Menumbuhkan Nilai Karakter Melalui Strategi Pembiasaan Di PPSA Tegal

Moh. Toharudin ${ }^{1}$, Laelia Nurpratiwiningsih ${ }^{2}$, Gian Fitralisma ${ }^{3}$

${ }^{(1,2)}$ Program Studi Pendidikan Guru Sekolah Dasar, Fakultas Keguruan dan Ilmu Pendidikan Universitas Muhadi Setiabudi

${ }^{3}$ Program Studi Manajemen, Fakultas Ekonomi dan Bisnis, Universitas Muhadi Setiabudi) $\quad$ 1-7

Menstimulasi Kemampuan Berbicara Pada Anak Usia Dini Berbasis Media Dongeng Agnes Apryliana ${ }^{1}$, Kiki Purwati ${ }^{2}$

${ }^{(1,2)}$ Program Studi Pendidikan Bahasa dan Sastra Indonesia, Fakultas Keguruan dan Ilmu Pendidikan, Universitas Muhadi Setiabudi)

Pemanfaatan E-Commerce Terhadap Penjualan Kendang Jimbe Blitar Harliana $^{1)}$, Roby Setiadii ${ }^{2}$, Otong Saeful Bachri ${ }^{3)}$, Khalid Iskandar ${ }^{4)}$, Gagas Prasetya ${ }^{5)}$ ${ }^{(1,3,5)}$ Program Studi Teknik Informatika, Fakultas Teknik, Universitas Muhadi Setiabudi ${ }^{2,4)}$ Program Studi Manajemen, Fakultas Ekonomi dan Bisnis, Universitas Muhadi Setiabudi) 15-20

Manajemen Tatakelola BUMDES: Mengelola Pemasaran Produk

Andi Yulianto ${ }^{1)}$, Mukson ${ }^{2)}$, Otong Saeful Bachri ${ }^{3)}$, Slamet Bambang Riono ${ }^{4)}$, Yenny Ernitawati ${ }^{5)}$ ${ }^{(1,2,4)}$ Program Studi Manajemen, Fakultas Ekonomi dan Bisnis, Universitas Muhadi Setiabudi ${ }^{5)}$ Program Studi Akuntansi, Fakultas Ekonomi dan Bisnis, Universitas Muhadi Setiabudi)

${ }^{3)}$ Program Studi Teknik Informatika, Fakultas Teknik, Universitas Muhadi Setiabudi)

Penggunaan Kartu Huruf dan Peramainan Mencari Kartu Huruf Untuk Peningkatan Pengenalan Huruf

Muhammad Toha $^{1)}$, Armyta Puspitasari ${ }^{2}$, Ubaedillah ${ }^{3)}$, Farhan Saefudin Wahid ${ }^{4)}$, Laelia Nurpratiwiningsih ${ }^{5}$

${ }^{(1,3)}$ Program Studi Pendidikan Bahasa dan Sastra Indoensia, Fakultas Keguruan dan Ilmu Pendidikan, Universitas Muhadi Setiabudi,

2)Teknologi Bangunan dan Jalur Perkretaapian, Politeknik Perkretaapian Indonesia,

${ }^{4,5}$ Program Studi Pendidikan Guru Sekolah Dasar, Fakultas Keguruan dan Ilmu Pendidikan, Universitas Muhadi Setiabudi)

${ }^{3)}$ Program Studi Manajemen, Fakultas Ekonomi dan Bisnis, Universitas Muhadi Setiabudi)

$28-33$ 


\section{Menumbuhkan Sikap Sadar Lingkungan Bagi Anak Usia Sekolah Dasar}

Laelia Nurpratiwiningsih ${ }^{1)}$, Teguh Arifianto ${ }^{2)}$, Wildan Qosid ${ }^{3)}$, Ubaedillah ${ }^{4)}$

(1,3)Program Studi Pendidikan Guru Sekolah Dasar, Fakultas Keguruan dan Ilmu Pendidikan, Universitas Muhadi Setiabudi,

${ }^{2)}$ Teknologi Elektro Perkretaapian, Politeknik Perkretaapian Indonesia,

$\left({ }^{4}\right.$ Program Studi Pendidikan Bahasa dan Sastra Indonesia, Fakultas Keguruan dan Ilmu Pendidikan,

Universitas Muhadi Setiabudi)

Peningkatan Pengetahuan Mengenai Manfaat Pangan Probiotik dan Prebiotik Bagi Kesehatan

Rifatul Masrikhiyah ${ }^{1)}$, Henry Widya Prasetya ${ }^{2)}$, Ubaedillah $^{3)}$, Rifqi Ferry Balfas ${ }^{4}$, Susi Yulianingsih ${ }^{5)}$ ${ }^{1,5}$ Program Studi Ilmu Gizi, Fakultas Kesehatan, Universitas Muhadi Setiabudi,

${ }^{2)}$ Teknologi Mekanika Perkretaapian, Politeknik Perkretaapian Indonesia,

${ }^{3}$ Program Studi Pendidikan Bahasa dan Sastra Indonesia, Fakultas Keguruan dan Ilmu Pendidikan, Universitas Muhadi Setiabudi,

4)Program Studi Ilmu Gizi, Fakultas Ilmu Kesehatan, Universitas Muhadi Setiabudi) $\quad$ 42-46

\section{Pelatihan Wawancara Kerja Dalam Bahasa Inggris Bagi Siswa SMK Menggunakan}

Metode Demonstrasi

Ubaedillah $^{1)}$, Damar Isti Pratiwi ${ }^{2)}$, Mukson $^{3)}$, Rifatul Masrikhiyah ${ }^{4)}$, Laelia Nurpratiwiningsih ${ }^{5)}$

( ${ }^{1}$ Program Studi Pendidikan Bahasa dan Sastra Indonesia, Fakultas Keguruan dan Ilmu Pendidikan, Universitas Muhadi Setiabudi,

2) Teknologi Mekanika Perkretaapian, Politeknik Perkretaapian Indonesia.

${ }^{3}$ Program Studi Manajemen, Fakultas Ekonomi dan Bisnis, Universitas Muhadi Setiabudi,

${ }^{4)}$ Program Studi Ilmu Gizi, Fakultas Ilmu Kesehatan, Universitas Muhadi Setiabudi

${ }^{5)}$ Program Studi Guru Sekolah Dasar, Fakultas Keguruan dan Ilmu Pendidikan, Universitas Muhadi Setiabudi) 


\title{
PELATIHAN WAWANCARA KERJA DALAM BAHASA INGGRIS BAGI SISWA SMK MENGGUNAKAN METODE DEMONSTRASI
}

\author{
Ubaedillah*1, Damar Isti Pratiwi $^{2}$, Mukson ${ }^{3}$, Rifatul Masrikhiyah ${ }^{4}$, Laelia \\ Nurpratiwiningsih ${ }^{5}$ \\ ${ }^{1}$ Program Studi Pendidikan Bahasa dan Sastra Indonesia, Fakultas Keguruan dan Ilmu \\ Pendidikan, Universitas Muhadi Setiabudi Brebes, Indonesia \\ ${ }^{2}$ Teknologi Mekanika Perkretaapian, Politeknik Perkretapaian Indoneisa \\ ${ }^{3}$ Program Studi Manajemen, Fakultas Ekonomi dan Bisnis, Universitas Muhadi Setiabudi \\ Brebes, Indonesia \\ ${ }^{4}$ Program Studi Gizi, Fakultas Kesehatan, Universitas Muhadi Setiabudi Brebes, Indonesia \\ ${ }^{5}$ Program Guru Sekolah Dasar, Fakultas Keguruan dan Ilmu Pendidikan, Universitas Muhadi \\ Setiabudi Brebes, Indonesia \\ e-mail: *11 ubaedillah2@ gmail.com, ${ }^{2}$ damar@ppi.ac.id, ${ }^{3}$ mukson@umus.ac.id, \\ rifatul.m@umus.ac.id, ${ }^{5}$ laelia.np@umus.ac.id
}

\begin{abstract}
In this period, the opportunity to get a job has been very competitive. Many companies only look for the highest quality human resources for recruiting new employees. The tendency to use international standards requires that prospective employees have high quality and competence in their fields. English language skills are a priority requirement for a company to choose human resources. English job interviews are a tool to test the English skills of job seekers. however, job interview skills are not widely taught in formal schools. But today an English job interview must be faced for every job seeker, especially in most large or foreign companies. Ma'arif Vocational School in Cirebon district has many students majoring office administration. After graduating from school they are prepared to work in companies. So, they need English language knowledge the skills to have an English job interview to get a job in a good place. The purpose of the program is English job interview training for 30 students of office administration department 12th grade at SMK Ma'arif using lecture and demonstration methods. This method contains tips and tricks for facing an English Job Interview using demonstration methods and a direct simulation of the English Job Interview process. Therefore this training has many advantages over their needs and it will be effective for their daily activities. This training also provides the main lesson for job interview questions that are frequently used and how to answer them. Using this training, it is hoped that they will have enough perspective, knowledge, and skills in dealing with job interviews at foreign companies.
\end{abstract}

Keywords: English Job Interview training, Demonstration.

\section{PENDAHULUAN}

UU RI No. 20 Tahun 2003 Tentang Sistem Pendidikan Nasional Pasal 3 ayat II yang menyatakan bahwa "Pendidikan Nasional berfungsi mengembangkan kemampuan dan membentuk watak serta peradaban bangsa yang bermartabat dalam rangka mencerdaskan kehidupan bangsa, bertujuan untuk berkembangnya potensi peserta didik agar menjadi manusia yang beriman dan bertakwa kepada Tuhan Yang Maha Esa, berakhlak mulia, sehat, berilmu, cakap, kreatif, mandiri, dan menjadi warga negara yang demokratis serta bertanggung jawab.

Persaingan untuk meraih pekerjaan di era sekarang semakin ketat. Seorang calon tenaga kerja tidak hanya dituntut untuk memenuhi kriteria mahir dalam bidang pekerjaan yang dituju, tetapi juga harus memiliki ketrampilan berkomunikasi 
menggunakan bahasa asing internasional yaitu bahasa Inggris. Seseorang yang mempunyai kemampuan berkomunikasi dengan bahasa Asing lebih berkesempatan untuk mendapatkan perkerjaan yang di inginkan, terutama untuk perusahaan Asing. Hal ini berpengaruh terhadap proses seleksi sebuah perusahaan ketika menetapkan persyaratan penerimaan karyawan baru. Ketrampilan berkomunikasi dalam bahasa Inggris sebagai salah satu syarat penerimaanya. Oleh karena itu, pentingnya sekolah untuk melakukan pelatihan berkomunikasi dalam bahasa Inggris agar lulusan dari sekolah tersebut mampu bersaing untuk mendapatkan pekerjaan yang bagus di kemudian hari.

Ditinjau dari segi ekonomi, manajemen suatu perusahaan memiliki kewajiban alamiah untuk mematuhi hokum dasar ekonomi, yaitu mencapai keuntungan maksimal dengan pengorbanan yang minimal. Efektifitas dan efisiensi kerja serta pengendalian mutu yang baik bisa menjamin perolehan margin keuntungan yang lebih besar, namun sedikit kelalaian dalam proses produksi, bisa menimbulkan suatu insiden, bagaimanapun disifatnya akan memberikan kontribusi pengorbanan yang cukup besar. (Sahat\&Daniel, 2011)

Dalam situasi ini terdapat permasalahan yang dihadapi mitra Pengabdian Masyarakat yaitu siswa-siswi SMK Ma'arif adalah sebagai berikut;

1. Kurangnya Pemahaman mengenai dunia kerja internasional

2. Kurangnya pemahaman mengenai cara menjawab interview Bahasa degnan Inggris

3. Kurangnya praktek Conversation dalam bahasa Inggris

4. Kurangnya sumber pendukung dalam pembelajaran job interview bahasa Inggris, sehingga wawasan peserta masih kurang.

Menurut Ayocirebon.com calon tenaga kerja yang menguasai teknologi informasi (IT) dan bahasa, terutama bahasa asing, merupakan yang paling banyak dibutuhkan perusahaan penyedia lapangan kerja di Kota Cirebon saat ini. Kepala Dinas Tenaga Kerja (Disnaker) Kota Cirebon, Agus Sukmanjaya mengungkapkan, rata-rata perusahaan di Kota Cirebon, bahkan di kota-kota lain, merupakan perusahaan berbasis IT. Untuk bahasa, calon tenaga kerja dengan penguasaan bahasa asing seperti Inggris, Jepang, Cina, hingga Arab, juga banyak dicari. Oleh karena itu perlu dilakukan kegiatan pelatihan yang terkait dengan kesiapan melaksanakan wawancara kerja berbahasa Inggris.

Sumber daya manusia yang berkualitas, merupakan salah satu aspek utama yang dibutuhkan dalam menjalankan roda perusahaan untuk mencapai suatu keberhasilan perusahaan. Tiap perusahaan memerlukan suatu perencanaan akan kebutuhan sumber daya manusia. Perencanaan tersebut tidak hanya berupa seberapa banyak kebutuhan akan tenaga kerja yang diperlukan untuk mengisi tiap jabatan pekerjaan dalam perusahaan tersebut, namun juga bagaimana kualitas personel yang dibutuhkan yang sesuai untuk menjalankan pekerjaan untuk tiaptiap jabatan tersebut. (Sahat\&Daniel, 2011)

Setiap lembaga penilaian, menyebutkan bahwa wawancara adalah metode yang dapat dirancang untuk menilai berbagai nilai predikat (Arthur \& Villado, 2008). Karakteristik yang dinilai dalam wawancara memberikan cerminan penting untuk pekerjaan itu sendiri.

Untuk itu tujuan kegiatan pengabdian masyarakat ini adalah memberikan solusi siswa-siswi SMK Ma'arif Kabupaten Cirebon, dengan melalui pelatihan menggunakan metode demonstrasi pembelajaran Bahasa Inggris berupa percakapan dalam wawancara kerja berbahasa Inggris yang diharapkan dapat bermanfaat untuk menghadapi wawancara kerja berbahasa Inggris di instansi atau perusahaan baik negeri maupun swasta sebagai bekal menghadapi persaingan menjadi pelamar kerja.

Target dari kegiatan Program Pengabdian Kepada Masyarakat bagi SMK Ma'arif kabupaten Cirebon ini adalah;

1. Meningkatkan kemampuan wawancara kerja dalam bahasa Inggris siswa-siswi jurusan administrasi perkantoran SMK Ma'arif melalui pembelajaran demonstrasi 
2. Dengan meningkatnya kemampuan wawancara kerja dalam bahasa Inggris, diharapkan para peserta memiliki bekal dan ketrampilan yang cukup sebagai pemenuhan persyaratan diterima di perusahaan perusahaan atau instansi baik negeri ataupun swasta.

3. Memberikan materi wawancara kerja berbahasa Inggris sebagai pengetahuan. Memberikan pelatihan secara intensif wawancara kerja bahasa Inggris, sehingga peserta mampu melakukan wawancara kerja dalam bahasa Inggris dengan baik.

4. Membantu mempersiapkan peserta dalam bersikap, berpenampilan, dan berpengetahuan tentang tata cara menghadapi wawancara kerja dalam bahasa Inggris.

5. Membagikan materi tentang wawancara bahasa Inggris kepada guru ataupun peserta akan pentingnya dan bermanfaatnya pelatihan sehingga dapat diaplikasikan dalam pembelajaran bahasa Inggris di sekolah selanjutnya

\section{METODE PELAKSANAAN}

Sumber data primer dan teknik pengumpulan data lebih banyak pada observasi berperan serta (participant observaction), wawancara mendalam (in depth interview), dan dokumentasi (Sugiono, 2017). Pada dasarnya kegunaan data (setelah diolah dan dianalisis) ialah sebagai dasar yang objektif didalam proses pembuatan keputusan-keputusan/ kebijaksanaan-kebijaksanaan dalam rangka ntuk memecahkan persoalan oleh pengambil keputusan (Situmorang, 2010).

Metode pendekatan yang digunakan sebagai solusinya adalah melalui 5 tahap kegiatan yaitu:

1. Observasi

Pada tahapan ini penulis mencari data dan informasi di lapangan terkait kebutuhan dan permasalahan yang ada di lokasi pengabdian masyarakat menggunakan metode wawancara singkat. observasi menjadi sebuah hal yang perlu dan menjadi keharusan bagi berkembangnya ilmu pengetahuan (Denzin, dan Lincoln, 2009: 523)

2. Studi pustaka
Pencarian literatur digunakan sebagai bahan buku dan referensi terkait penggunaan materi atau bahan ajar yang digunakan dan pelatihan yang akan diaplikasikan dalam kegiatan pengabdian masyarakat.

\section{Pelatihan}

Pelatihan adalah tahap pemberian materi dan pelatihan melalui metode demonstrasi kepada mitra Pengabdian Kepada Masyarakat. Adapun tahapan yang diberikan adalah

a) Pengenalan mengenai pertanyaanpertanyaan apa saja yang biasa keluar dalam interview dalam bahasa Inggris dan cara menjawab pertanyaan-pertanyaan tersebut.

b) Praktik interview dalam bahasa Inggris

\section{Evaluasi dan pendampingan}

Tahap evaluasi berfungsi sebagai tes keberhasilan peserta dan melihat perkembangan dalam proses belajar tentang wawancara kerja dalam bahasa Inggris.

Penulis memberikan materi secara detail tentang tips dan trik secara umum dan bagaimana memunculkan percaya diri untuk menghadapi wawancara kerja dalam bahasa Inggris. Banyak hal yang banyak ditanyakan oleh peserta pelatihan karena menurut 30 siswa-siswi SMK Ma'arif Kabupaten Cirebon sebagai repsonden, mengemukakan bahwa kesulitan utama yang dihadapi dalam belajar berbicara bahasa Inggris yaitu pengucapan atau pronunciation. Penguatan materi menggunakan media demonstrasi Job Interview dalam penyampaian materi yang lebih Kreatif dan inovatif. Para peserta pelatihan sangat antusias dalam mengikuti penyampaian materi.

Metode demonstrasi adalah metode mengajar dengan cara memperagakan barang, kejadian, aturan, dan urutan melakukan suatu kegiatan, baik secara langsung maupun melalui penggunaan media pengajaran yang relevan dengan pokok bahasan atau materi yang sedang disajikan. (Hurrahman\& Fat, 2008). Metode ini digunakan agar siswa menjadi lebih paham terhadap materi yang dijelaskan karena menggunakan alat peraga dan 
menggunakan media visualisasi yang dapat membantu siswa untuk lebih memahami. (Dedi dkk,2010)

Pelaksanaan Program dan Peran Mitra adalah:

1. Tim pelaksana pengabdian melalui program Pengabdian Kepada Masyarakat ini adalah menyusun materi berupa tips dan trik job interview dalam bahasa Inggris.

2. Tim pelaksana Pengabdian Kepada Masyarakat melibatkan guru Bahasa Inggris SMK Ma'arif sebagai mitra dalam pelaksanaan pelatihan.

3. Peran mitra secara aktif mengikuti dengan seksama pelatihan oleh tim pelaksanaan program Pengabdian Kepada Masyarakat kepadamitra.

4. Mitra pengabdian mengaplikasikan hasil pelatihan melalui metode demonstrasi interview kerja dalam bahasa Inggris berdasarkan tips dan trik yang diberikan oleh tim pelaksana pengabdian masyarakat.

5. Evaluasi dan pendampingan dilakukan setelah kegiatan pelatihan dilaksanakan. Peran guru dalam pelaksanaan program kedepan adalah secara aktif dan terencana untuk memberikan materi job interview sebagai bahan ajar dan media pembelajaran bahasa Inggris di SMK Ma'arif Cirebon.

\section{HASIL DAN PEMBAHASAN}

Menurut Muhibbin Syah (2010:205), "Metode demonstrasi adalah metode mengajar melalui peragaaan barang, kejadian, aturan, dan urutan melakukan suatu kegiatan baik secara langsung maupun melalui penggunaan media pengajaran yang relevan dengan pokok bahasan atau materi yang sedang disajikan". Dengan demikian, metode demonstrasi dalam hal ini merupakan metode mengajar yang lebih menekankan pada praktik pengajaran secara langsung melalui media atau alat peraga untuk menyampaikan materi pelajaran kepada siswa. Adapun hasil dan pembahasan pada pengabdian kepada masyarakat yang dilakukan di SMK Ma'arif adalah sebagai berikut;

\section{Observasi}

Pada tahapan observasi melalui wawancara pada responden tentang wawancara kerja sebagian besar mereka belum pernah mendapatkan materi wawancara kerja bahasa Inggris di sekolah. Di samping itu mereka tidak pernah menemui pelatihan ataupun workshop tentang wawancara kerja bahasa Inggris. Pengetahuan tentang Sumber belajar pun sangat kurang sehingga mereka tidak tahu harus bagaimana untuk berlatih dan belajar percakapan tentang wawancara kerja dalam bahasa Inggris. Padahal mereka sangat membutuhkan hal tersebut untuk mempersiapkan diri dalam menghadapinya apabila dipanggil wawancara kerja.

Fungsi observasi secara lebih rinci dijelaskan oleh Rahmat (2005: 84) terdiri dari deskripsi, mengisi, dan memberikan data yang dapat digeneralisasikan. Deskripsi, berarti observasi digunakan untuk menjelaskan, memberikan, dan merinci gejala yang terjadi, seperti seorang laboran menjelaskan prosedur kerja atom hidrogen, atau ahli komunikasi menjelaskan secara rinci prosedur kerja di stasiun televisi. Mengisi data, memiliki maksud bahwa observasi yang dilakukan berfungsi melengkapi informasi ilmiah atas gejala sosial yang diteliti melalui teknik-teknik penelitian. Memberikan data yang dapat digeneralisasikan, maksudnya adalah setiap kegiatan penelitian, sehingga mengakibatkan respon atau reaksi dari subjek amatan.

\section{Studi Pustaka}

Pada Tahapan studi pustaka, tim mengumpulkan literature tentang media pembelajaran dan materi tentang wawancara kerja dalam bahasa Inggris. Dari hasil studi pustaka diperoleh informasi tentang Media pembelajaran Menggunakan metode demonstrasi untuk menyampaikan materi atau pesan kepada siswa yang dapat merangsang pemikiran, perasaan, perhatian dan keinginan sehingga pembelajaran dapat tercapai dengan baik.

Materi wawancara kerja yang disampaikan yaitu tentang apa itu Wawancara Kerja (Job Interview), Persiapan yang harus dilakukan dalam wawancara kerja yaitu Persiapan fisik dan 
mental. Persiapan fisik berupa penampilan dan dokumen kelengakapan persyaratan kerja, persiapan mental berupa percaya diri. Mempelajari pertanyaan-pertanyaan yang sering muncul dalam proses wawancara kerja beserta jawabannya, dan di aplikasikan melalui demonstrasi job interview dalam bahasa Inggris.

Tim pelaksana menyiapkan materi secara detail tentang tips dan trik secara umum dan bagaimana memunculkan percaya diri untuk menghadapi wawancara kerja dalam bahasa Inggris. Banyak hal yang ditanyakan oleh peserta karena menurut mereka banyak kesulitan yang dihadapi dalam belajar berbicara bahasa Inggris terutama pengucapan atau pronunciation. Namun video tersebut cukup membantu mereka dalam penguatan materi serta memberikan model Job Interview dalam penyampaian materi yang lebih kreatif dan inovatif. Para peserta pelatihan sangat antusias dalam mengikuti penyampaian materi dari tim pelaksana.

\section{Pelatihan}

Pelaksanaan Pelatihan pengabdian masyarakat ini dilakukan pertama-tama adalah mempersiapkan materi untuk pelaksanaan. Kemudian tim mulai melaksanakan :

a. Memberikan pengarahan tentang tahaptahap pelatihan wawancara kerja. Kemudian tim menyampaikan materi tahap pertama yaitu tentang tips dan trik mempersiapkan wawancara kerja, etika, penampilan, dan performa dalam memenuhi dan menghadapi wawancara kerja. Banyak peserta yang terlihat puas dan antusias dalam pembahasan ini.

b. Menyampaikan materi bahasa Inggris seperti grammar, vocabulary, kalimat bahasa Inggris, pertanyaan-pertanyaan serta jawaban yang sering muncul dalam job interview. Beberapa peserta banyak bertanya terutama tentang pengucapan serta tata bahasa yang tidak banyak dari peserta yang paham betul. Tanya jawab berlangsung seru. Mereka sangat antusias mengikutinya.

c. Demonstrasi wawancara kerja dalam bahasa Inggris secara manual dan juga memberi penguatan dengan menggunakan slide dan video tutorial. Kemudian peran mitra adalah mengaplikasikan apa yang ada dalam video tutorial tersebut sebagai materi pembelajaran praktek wawancara kerja dalam bahasa Inggris.

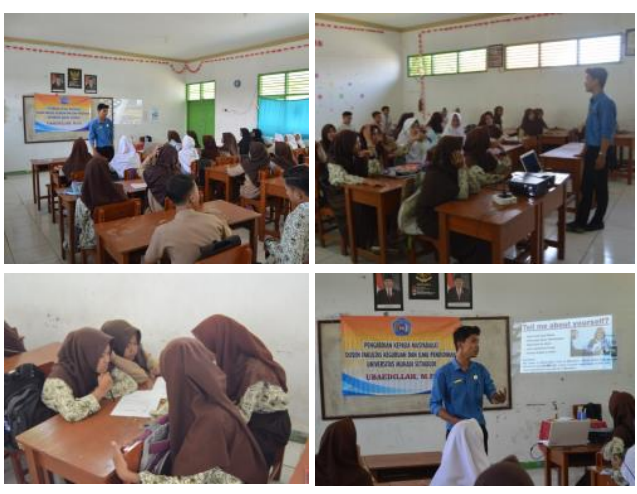

Gambar 1. Pelatihan Wawancara Kerja dalam Bahasa Inggris

\section{Evaluasi dan Pendampingan}

Evaluasi dan pendampingan materi wawancara kerja dalam bahasa Inggris terhadap tiap peserta untuk mengetahui capaian luaran yang dihasilkan pengaplikasian materi yang disampaikan sebagai penguat pembelajaran peserta dan dimasukan kedalam Indikator pembelajaran dalam bahasa Inggris di SMK Ma'arif Kabupaten Cirebon. Tim pelaksana program pengabdian masyarakat memberikan pendampingan yang berakhir dengan mengevaluasi terhadap tiap peserta. Untuk selanjutnya, proses belajar mengajar berjalan lancar. Para siswa terlihat sangat tertarik dan antusias saat media pembelajaran ini digunakan. Sehingga tercipta suasana belajar yang aktif dan meningkatkan motivasi pesrta pelatihan. Interaksi antara tim dan peserta sangat komunikatif dengan adanya media ini.

\section{UCAPAN TERIMAKASIH}

Dengan memanjatkan puji syukur kehadirat Allah SWT kami dapat menyelesaikan pengabdian masyarakat ini dengan baik.

Pada kesempatan ini kami juga mengucapkan terima kasih atas 
kontribusinya dalam penyelesaian program Pengabdian Kepada Masyarakat kepada :

1. Dr. Moh. Toharudin, M.Pd. selaku Kepala LP3M Universitas Muhadi Setiabudi

2. Bapak Asrori, S.Pd. Selaku Guru Bahasa Inggris di SMK Ma'arif Kabupaten Cirebon Serta bagi semua yang terlibat dalam pelaksanaan Program pengabdian masyarakat ini.

\section{KESIMPULAN}

Dari keseluruhan kegiatan pengabdian kepada masyarakat ini, dapat ditarik kesimpulan:

1. Pelatihan wawancara kerja dalam bahasa Inggris ini memberikan pembekalan materi yang sangat berguna bagi mitra.

2. Meningkatkan percaya diri dalam memenuhi panggilan wawancara kerja dan menghadapi wawancara kerja

3. Memberikan wawasan yang cukup tentang pengetahuan seputar wawancara kerja, tips dan trik menghadapi wawancara kerja

4. Meningkatkan kemampuan peserta dalam praktek berbicara bahasa Inggris terutama wawancara kerja.

5. Memberikan luaran untuk kebutuhan guru SMK Ma'arif sebagai bahan ajar pelatihan wawancara kerja dalam bahasa Inggris.

\section{DAFTAR PUSTAKA}

Undang-Undang Republik Indonesia Nomor 20 Tahun 2003 Tentang Sistem Pendidikan Nasional

Sahat, Daniel. (2011). Analisis Perekrutan Dan Seleksi Tenaga Kerja di Pt. 'Toray' Istem. Jurnal Ilmiah Faktor Exacta. 317-276, Vol. 4 No. 4 Desember 2011

Erika Lia. AyoCirebon.com. 2019. Skill Ini Paling Dicari Penyedia Lapangan Kerja di Kota Cirebon, pada URL https://www.ayocirebon.com/read/20 19/04/03/2353/skill-ini-paling-dicaripenyedia-lapangan-kerja-di-kotacirebon. Editor : Fira Nursyabani
Muhibbin Syah. (2010). Psikologi Pendidikan. Bandung : PT Remaja Rosdakarya.

Denzin, Norman K., \& Lincoln, Yvonna S., (ed.), Handbook of Qualitative Research, 2nd editions, New Delhi, Teller Road Thousand Oaks, California, USA: Sage Publication, Inc., 2009.

Rahmat, Jalaluddin, Metode Penelitian Komunikasi, Bandung: PT. Rosdakarya,

2005.

Sugiyono. (2017). Metode Penelitian Kuantitatif, kualitatif dan $R \& D$. Bandung: Alfabeta.

Situmorang, S. H. (2010). Analisis Data untuk Riset Menejemen dan Bisnis. Medan: USU Press.

Dedi dkk. (2010). Efektivitas Metode Pembelajaran Demonstrasi Terhadap Peningkatan Hasil Belajar Siswa Kelas X Pada Mata Pelajaran Keterampilan Komputer dan Pengelolaan Informasi Di Sekolah Menengah Kejuruan. JURNAL PENDIDIKAN TEKNOLOGI INFORMASI DAN KOMUNIKASI (PTIK). ISSN 1979-9462. Vol. 3 No.1 / Juni 2010 p.16-18.

Hurrahman, Fat. (2008). Metode Demonstrasi dan Eksperimen [Online]. Tersedia http://udhiexz.wordpress.com/2008/0 8/08/metodedemonstrasi-danekspermen/ [8 agustus 2008]. 